\title{
Synchronization and management of material flows in small-scale production
}

\author{
A Vozhakov \\ ERP Department \\ Ltd «1C-Soft» \\ Perm, Russia \\ vozhakov@ya.ru
}

\author{
M Gitman \\ Department of Computational Math and Mechanics \\ Perm National Research Polytechnic University \\ Perm, Russia \\ gmb@pstu.ru
}

\author{
V Stolbov \\ Department of Computational Math and Mechanics \\ Perm National Research Polytechnic University \\ Perm, Russia \\ valeriy.stolbov@gmail.com
}

\begin{abstract}
The mathematical problem of synchronization of material flows in small-scale production is a statement of objectives, criteria and optimization demonstration. It is proposed to use the best practices of Lean and QRM approach as applied to small-scale production, taking into account the specifics. There is an approach to the optimization of production by creating a module synchronization of material flows in accordance with the mathematical formulation of production problems of synchronization. The criterion of maximizing the priorities of current orders and criteria for prioritization of work with minimal planned start time is used. The authors considered a test case that illustrates the principle of synchronized production management systems in ever-changing production conditions. The authors demonstrated the selected virtual production system, consisting of five production sites. Using the synchronized production management system allowed one to profit from the execution of orders by $30 \%$ higher than without it. When assessing the level of work in progress, and the time and the amount of frozen assets, it becomes obvious that the use of a synchronized control system allows you to reduce the time and other direct and indirect costs, which exerts more positive impact on the net profit of the enterprise. Synchronization module production is seen as an additional ERP module built into the existing ERP.
\end{abstract}

Keywords- material flow, optimization, pull system, smallscale production, Lean, QRM, ERP

\section{INTRODUCTION}

Present time, in contrast to the past, sets new rules for manufacture management. It is time of product customization, which requires manufacturers to reduce the size of the batch, be ready to manufacture new products, work for individual orders. Volatility of market aggravates the situation. Enterprise management receives new challenges, especially if manufacture is complex, if many details are included in its composition, if process chains are long. Manufacturing execution systems (ERP [1, 3]/ MES [2]), optimization practice of manufacture processes (Lean [4], TOC [5], QRM
[6]) have been developed for the past twenty years. However, these practices work well only for mass line manufacture [7] and are not applied to small-scale manufacture of complex high-tech products. The efficiency of this type of manufacture remains low, there is extremely a lot of losses, there are long cycles of manufacture and high inventory levels at all stages of manufacture [8].

Pull System - a scheduling system where inventory is limited in some way, push system - a scheduling system where inventory is not formally limited. Most businesses do not put hard limits on their inventories. Without a limit, the amount and location of inventory at any given time is fairly random and will tend to grow as time goes on [10]. ERPsystem is a Push system [10], material resources are "pushed" from one part of the manufacture logistics system to another. Each operation schedule common to set the time by which it must be completed. The resulting product is "pushed" further and becomes margin WIP next input operation. Once calculated plan is mandatory for manufacture.

The Quick Response Manufacture [6] proposes POLCA control system (overlap cycles interaction pairwise connected cells by means of cards, authorization, paired-cell overlapping loops of cards with authorization), designed for use in smallscale manufacture, organized by QRM principles, which on the one hand, uses the plan calculated in the ERP system to determine the scope of work and circulating cards cell pairs that are in single chain works. Task cards are similar to the supermarket, but adapted to small-scale manufacture - if the manufacture unit (plant, cell, work center) does not have a card from the user - it can not do the work, and when there is a card - unit executes a plan from the ERP system.

But this method will not work, if manufacture is not reorganized with a QRM strategy. This requires the work method to optimize scheduling in small-scale manufacture without additional restrictions on use. 


\section{CONCEPTUAL FORMULATION}

As the model object, let us consider small-scale discretestop manufacture with a wide range of highly-diverse product nomenclature.

Manufacture is organized in several shops $n \in \overline{1, N}$ where $\mathrm{N}$ - total number of plants, which in turn are divided into manufacturing areas $\mathrm{k} \in \overline{1, \mathrm{~K}}$ where $\mathrm{K}$ - number of stations in all the shops in which concentration of a certain amount of process equipment is united by usage of technological operations, or on the principle of formation of QRM cells. At the same time, to ensure manageability, the plot size is not too large in scale of manufacture. We introduce the portion belonging shop via $n_{k}, k \in \overline{1, K}$ - shop number, in which there is a portion [9].

Figure 1 shows an example of manufacture and the division into sections; the arrows indicate the main direction of motion of the material flow forming process in the manufacture chain. Analysis of processing chains is crucial for the construction of the efficient manufacture process and for synchronizing manufacture in particular.

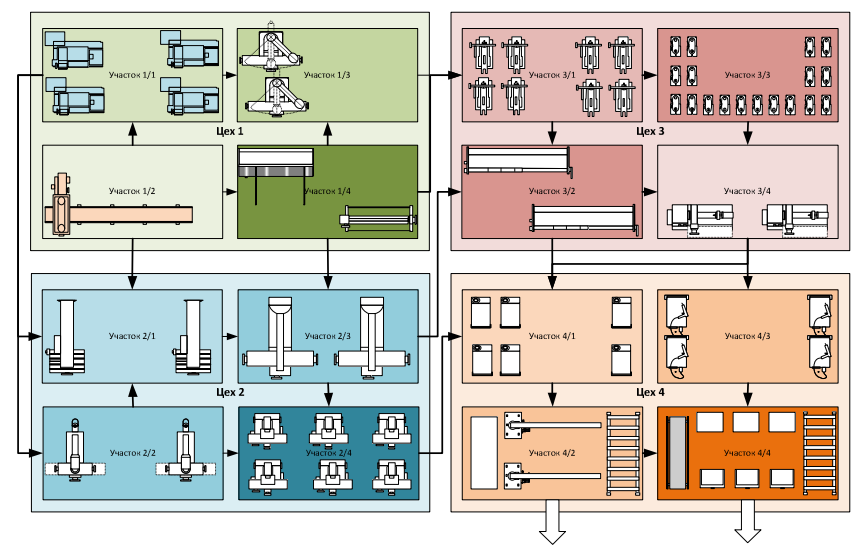

Fig. 1. An example of manufacture and dividing into sections

It is believed that the company has implemented an automated enterprise management system based on the standard for the MRP II data model:

- resource specifications for products and semi-finished products;

- technological fabrication routes that contain at least the processing route of parts and assemblies and an expandable list of technological operations and indicating the complexity of the equipment used;

- the calendar specifications duration route transitions;

- the main schedule, which determines the need for the release of products by date needs, divided by customer orders and output parties inside the order;

- manufacture of parts and assemblies is carried batches whose size is determined in the ERP-system batch numbered index $p, p \in \overline{1, P}$.

For each batch of known processing route. We know the number of block transitions for each party $-m_{p}$ for each route section of the transition is defined by the Executive Room: $\mathrm{M}_{\mathrm{mp}}, \mathrm{m} \in \overline{1, \mathrm{~m}_{\mathrm{p}}}, \mathrm{p} \in \overline{1, \mathrm{P}}$

At any given time, we know the current status of work in progress. For each batch of parts, we defined the current routing transition $C_{p} \in \overline{0, m_{p}}$, where the value 0 corresponds to the state of completion of the processing of the party details.

Part of details proceeds to the next step immediately after the completion of processing at the previous stage, after the completion of the last stage of the current state automatically switches to state 0 , the transition current value changes according to formula (1):

$$
\mathrm{C}_{\mathrm{p}}^{*}=\left\{\begin{array}{c}
\mathrm{M}_{\mathrm{C}_{\mathrm{p}}+1 \mathrm{p}}, \mathrm{C}_{\mathrm{p}}<\mathrm{m}_{\mathrm{p}} \\
0, \mathrm{C}_{\mathrm{p}}=\mathrm{m}_{\mathrm{p}}
\end{array} .\right.
$$

For the current state of work in progress, more discrete state is determined, where 0 - batch transport step is in or acquisition; 1 - the party is on the workshop section, resourced and ready for processing; 2 - the party determined to fulfill; 3 - launched batch processing; 4 completed batch processing on the workshop section: $S_{p} \in\{0,1,2,3,4\}$.

It should be noted that the party status of going to the next state is irreversible, the transition of the party to the previous state is impossible.

For a more detailed account of the additional current status, states can be allocated in ERP-system, such as: incoming expectation, waiting for the start of processing, handling, etc. to be launched

For each party we defined the order priority, having aggregated information on the importance of a sales order, profitability, value and other parameters of the order, which affect the importance of the order for the enterprise $W_{p} \in[0,1]$, where one corresponding to the maximum value of the order is of importance.

Intended manufacture schedule is determined for each point of the route for each part details: the planned date of commencement of treatment $\mathrm{DP}_{\mathrm{mp}}$; duration of treatment $\mathrm{DL}_{\mathrm{mp}}$ and the planned effective date $\mathrm{DF}_{\mathrm{mp}}$ of the start of processing batches of parts in areas where: $\mathrm{m} \in \overline{1, \mathrm{~m}_{\mathrm{p}}}, \mathrm{p} \in \overline{1, \mathrm{P}}$.

For each batch of assemblies we identified a kit of parts, which will be included in the assembly and that must be completed for a successful start to build. Lot numbers, going to an assembly, are defined in the array: $\quad L_{p l} \in \overline{1, P}$, где $p \in \overline{1, P}, l \in \overline{1, l_{p}} \cdot l_{p} \quad$ is the number of preceding batches of parts. In this case, we must carry out restriction (2), making it impossible to translate the work state to the state of readiness for the implementation of $\left(S_{p}=1\right)$ the first transition $\left(C_{p}=1\right)$ assembly if a lot of unfinished $\left(\mathrm{C}_{\mathrm{L}_{\mathrm{pl}}}>0\right)$ precursors are not empty: 


$$
\begin{gathered}
\left\{\mathrm{L}_{\mathrm{pl}} \mid \mathrm{C}_{\mathrm{L}_{\mathrm{pl}}}>0, \quad l \in \overline{1, \mathrm{l}_{\mathrm{p}}}\right\} \neq \emptyset \Rightarrow \mathrm{C}_{\mathrm{p}} \\
=1 \wedge \mathrm{S}_{\mathrm{p}}=0, \mathrm{p} \in \overline{1, \mathrm{P}} .
\end{gathered}
$$

In accordance with the approach «just in time» section $\mathrm{k}$ can and should carry out the work manufacture plan $(\vec{F})$, which reached the date of commencement, and in a state of readiness to perform $\left(S_{p}=1\right)$, while in the status to perform $\left(S_{p}=2\right)$ transferred all the work for which the following conditions are satisfied:

$$
\overrightarrow{\mathrm{F}}=\left\{\mathrm{p} \mid \mathrm{t} \geq \mathrm{DP}_{\mathrm{C}_{\mathrm{p}} \mathrm{p}} \wedge \mathrm{S}_{\mathrm{p}}=1\right\} \text {. }
$$

However, manufacture management experience shows that blind adherence calculated in the ERP-system of manufacture as a consequence of the plan is inevitable deviations leading to skew areas of activity.

We introduce the concept of synchronization cards, designed to synchronize the activity areas in order to minimize the manufacture of unclaimed goods, excess inventory, increase responsiveness and reduce manufacture cycle times. The essence of the concept is similar cards POLCA, used in QRM [6], but the logic will be different, which requires separate isolation determination. A synchronization card has two mandatory attribute - portion sender and the recipient workshop section. Each portion (receiver) supplies at least one card for each portion, which is the supplier of the technological chains elements (assemblies) to the sector. The number of cards for a recipient provider may be increased if the material flow between the portions is particularly intense.

The number available for use of cards determines the synchronization of the array $\mathrm{K}_{\mathrm{k}_{1} \mathrm{k}_{2}}$, where $\mathrm{k}_{1}$ - the receiver portion, and $\mathrm{k}_{2}$ - a workshop section provider. The number of cards $\mathrm{k}_{2}$ used supplier $\mathrm{k}_{1}$ portion is determined by counting the number of lots of parts which are in the shop $\mathrm{k}_{1}$, which is the portion of the previous processing $\mathrm{k}_{2}$. At every point in time, the number of cards currently in use $\mathrm{K}_{\mathrm{k}_{1} \mathrm{k}_{2}}^{*}$ shall not exceed the number of available cards synchronization:

$$
\begin{gathered}
\mathrm{K}_{\mathrm{k}_{1} \mathrm{k}_{2}}^{*}=\sum_{\mathrm{p}=1}^{\mathrm{P}} \mathrm{q}\left(\mathrm{p}, \mathrm{k}_{1} \mathrm{k}_{2}\right) \leq \mathrm{K}_{\mathrm{k}_{1} \mathrm{k}_{2}}, \text { where } \mathrm{q}\left(\mathrm{p}, \mathrm{k}_{1} \mathrm{k}_{2}\right)= \\
\left\{\begin{array}{c}
1, \mathrm{M}_{\mathrm{C}_{\mathrm{p}} \mathrm{p}}=\mathrm{k}_{2} \wedge \mathrm{M}_{\mathrm{C}_{\mathrm{p}}+1 \mathrm{p}}=\mathrm{k}_{1} \wedge \mathrm{S}_{\mathrm{p}} \in[2,3] \\
0, \mathrm{M}_{\mathrm{C}_{\mathrm{p}} \mathrm{p}} \neq \mathrm{k}_{2} \vee \mathrm{M}_{\mathrm{C}_{\mathrm{p}}+1 \mathrm{p}} \neq \mathrm{k}_{1} \vee \mathrm{S}_{\mathrm{p}} \in[0,1,4]
\end{array}\right.
\end{gathered}
$$

If a certain operation is performed, $p\left(S_{p} \in[2,3]\right)$ in the area $\mathrm{k}_{2}\left(\mathrm{M}_{\mathrm{C}_{\mathrm{p}} \mathrm{p}}=\mathrm{k}_{2}\right)$ with subsequent transfer to the portion $\mathrm{k}_{1} \quad\left(\mathrm{M}_{\mathrm{C}_{\mathrm{p}}+1 \mathrm{p}}=\mathrm{k}_{1}\right)$ (it is considered that the synchronization uses one card $\mathrm{k}_{1} \mathrm{k}_{2}$ ).

There is need to develop a system of synchronization of manufacture, which is based on the information in the ERPsystem in a real-time and sends to the implementation of $\left(S_{p}=2\right)$ the optimal set of parties $\overrightarrow{F A}$, the implementation of which is most expedient at the current time $t$ based on drawing principles, restrictions on work in progress and prioritization orders.

In other words, one wants to define and translate to the implementation of such parties $\mathrm{p}^{*} \in \overrightarrow{\mathrm{FA}}$, for which the following conditions are met: $\mathrm{p}^{*} \in \overrightarrow{\mathrm{FA}}$

$$
\begin{aligned}
& \mathrm{p}^{*} \in \overrightarrow{\mathrm{F}}=\left\{\mathrm{p} \mid \mathrm{t} \geq \mathrm{DP}_{\mathrm{C}_{\mathrm{p}}} \wedge \mathrm{S}_{\mathrm{p}}=1\right\} \\
& \sum_{\mathrm{p}^{*} \in \overrightarrow{\mathrm{FA}}} \omega\left(\mathrm{p}^{*}, \mathrm{k}_{1}, \mathrm{k}_{2}\right)+\mathrm{K}_{\mathrm{k}_{1} \mathrm{k}_{2}}^{*} \leq \mathrm{K}_{\mathrm{k}_{1} \mathrm{k}_{2}} .
\end{aligned}
$$

where $\omega\left(\mathrm{p}, \mathrm{k}_{1}, \mathrm{k}_{2}\right)=$

$\left\{1, \mathrm{M}_{\mathrm{C}_{\mathrm{p}} \mathrm{p}}=\mathrm{k}_{2} \wedge \mathrm{M}_{\mathrm{C}_{\mathrm{p}}+1 \mathrm{p}}=\mathrm{k}_{1} \wedge \mathrm{C}_{\mathrm{p}}>1\right.$

$\{0$, else

$$
\begin{aligned}
& \mathrm{J}_{1}=\sum_{\mathrm{p}^{*} \in \overrightarrow{\mathrm{FA}}} \mathrm{W}_{\mathrm{p}^{*}} \rightarrow \max \\
& \mathrm{J}_{2}=\sum_{\mathrm{p}^{*} \in \overrightarrow{\mathrm{FA}}} \mathrm{DP}_{\mathrm{C}_{\mathrm{p}^{*}} \mathrm{p}^{*} \rightarrow \min }
\end{aligned}
$$

The above statement of the problem is a two-criteria optimization problem with two independent criteria. For the problem to be solvable, it is required to introduce a generalized criterion optimality of the plan. In practice, usually one of the criteria is selected as a "master", that is, having the highest importance. However, all experts agree on other criteria that can not be forgotten - they are all important. However, the ratio of importance of these criteria is very unclear. To solve this problem, a generalized optimality criterion may be used with a special fuzzy set extended over private optimality criteria $[11,12]$.

On the basis of the proposed, partial criteria may be introduced as a generalized optimality criterion with extended special fuzzy set over particular optimality criteria:

$$
\mathrm{J}^{\mathrm{r}}=\left\{\mu_{1} / \mathrm{J}_{1} ; \mu_{2} / \mathrm{J}_{2} ;\right\} \text { where } \mu_{1} \text { and } \mu_{2} \text { - the importance of }
$$
particular criteria $J_{1}$ and $J_{2}$ respectively. Let us note that $\mu_{i} \in[0,1], \mathrm{i}=1,2, \mathrm{r}$ - number of this variant of the manufacture plan. For definiteness, we assume that both private is necessary to minimize the optimality criterion. In this case it is sufficient for criteria (7) to change the sign to "".

Now, using the clear function of the fuzzy argument (special index ranking), comparison of variants of the manufacture plan $\mathrm{r} 1$ and $\mathrm{r} 2$ by the generalized criterion $\mathrm{Jr}$ can be carried out according to the formula:

$$
\mathrm{H}\left(\mathrm{J}^{\mathrm{r} 1}, \mathrm{~J}^{\mathrm{r} 2}\right)=\operatorname{sign} \mathrm{R}_{\mathrm{i}} \text {, where } \mathrm{R}_{\mathrm{i}}=\frac{\mu_{\mathrm{i}}^{\mathrm{r} 1} \cdot \mathrm{J}_{\mathrm{i}}^{\mathrm{r} 1}-\mu_{\mathrm{i}}^{\mathrm{r} 2} \cdot \mathrm{J}_{\mathrm{i}}^{\mathrm{r} 2}}{\max \left(\mathrm{J}_{\mathrm{i}}^{\mathrm{r} 1}, \mathrm{~J}_{\mathrm{i}}^{\mathrm{r}}\right)}
$$

Of all the values, $\mathrm{Ri}$ is a selected modulo of a maximum value, the sign of which determines the ranking of the index (9).

Now, if the value $\mathrm{H}\left(\mathrm{J}^{\mathrm{r} 1}, \mathrm{~J}^{\mathrm{r} 2}\right)=+$ then $\mathrm{J}^{\mathrm{r} 1}>\mathrm{J}^{\mathrm{r} 2}$ else $\mathrm{J}^{\mathrm{r} 1}<\mathrm{J}^{\mathrm{r} 2}$.

Thus the problem posed above is two-criteria discrete optimization can be reduced to the following single-criterion problem with the generalized fuzzy optimality criterion.

The party finds such optimal $\mathrm{p}^{*} \in \overrightarrow{\mathrm{FA}}$ at which the minimum of the generalized criterion:

$$
\mathrm{J}^{\mathrm{r}} \rightarrow \min
$$

and executed limit (5) and (6).

To solve the problem (10), different numerical methods discrete optimization may be used with rank index 
(9). However, in practice it is the transition from the optimization problem to the problem of choice on a given set of possible alternatives more convenient. In the above case, the number of allowable manufacture plans that satisfy the constraints (5) and (6), is small, which makes it possible to carry out such a transition and choose the best plan for directly using the index (9).

\section{EXAMPLE OF SYNCHRONIZED OPERATION SYSTEM}

Let us consider a simple example that illustrates the principle synchronized manufacture management systems in ever-changing manufacture conditions.

Let manufacture consist of five workshop section. At the moment considered, it is necessary to perform two orders that have the same priority on the two types of products (product $\mathrm{A}$ and product B) to 5 units of each type.

Both orders are to be shipped on the 10th week, and for the breakdown of the shipment period there are penalties in the amount of $3 \%$ of the contract value per week of delay. For clarity, let us assume that the cost of product " $\mathrm{A}$ " and " $\mathrm{B}$ " is the same. Also let us assume that the planned profitability of orders is $20 \%$ of the product cost.

Manufacture plans were calculated in ERP-system, but the supply of materials was delayed, which led to the later start of manufacture.

The article $« \mathrm{~A} »$ is processed in workshop sections 1,3 and 4. The product $« B »$ is processed at sections 2,3 and 5 . The processing time at each station is the same and a week. At each workshop section, only one article may be processed at one time. At the initial stage, there is no work in progress.

To begin with, let us consider the standard manufacture work with a known manufacture plan. Figure 2 is a manufacture work during the first three weeks; the plants appear to the left of residues product preforms right number of issued items "A" (Section 4), and B (Section 5). On top of the sections, there is the number of articles "A" located on the workshop section; at the bottom - the number of workshop section selling «B» located on the workshop section. The workshop section number 3 further shows how the product is processed during the current week " $\mathrm{A} "$ or $« \mathrm{~B} »$.

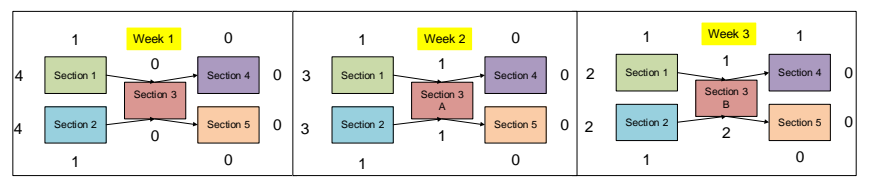

Fig. 2. First three weeks of the manufacture

On the first week of lots 1 and 2, one begins manufacture, the remaining portions of forced idle. In the second week, two semi $« A »$ and $« B »$ come on plot 3 . Since the two orders are not on schedule and have the same priority, the manufacture of the area is taken 3 prefabricated "A".

In the third week, semifinished product "A" starts the processing portion 4 , two more semifinished are provided to portion 3. Now the area 3 for 3 and the head portion semifinished product must select which of the three semi- finished products to be processed. In this example, we will assume that in order to respect the rhythm of manufacture, foreman decides to balance manufacture and alternate products "A" and "B". In a real situation, considering that the changeover takes time, section chief could decide to increase the batch processing and re-select the semi-finished product "A", which is just in stock. This would only aggravated the situation described below.

Next, let us consider how manufacture occurred within weeks 4-6 (Figure 3).

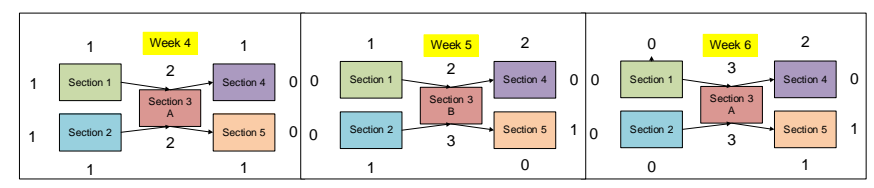

Fig. 3. Work manufacture in 4-6 weeks

Let us assume that on plot №4 having some organizational delays that have led to the fact that in week 4 (looking ahead, it will last up to a week №8), the product "A" was never released. As a rule, this information is not communicated to the allied units, which continue to operate under the current manufacture plan.

Lots 1 and 2 continue to run manufacture of articles each week, the number of unfinished items on the workshop section 3 is constantly increasing. One shall release the "B" items on the 5 th week.

Figure №4 provides information about the final period of manufacture:

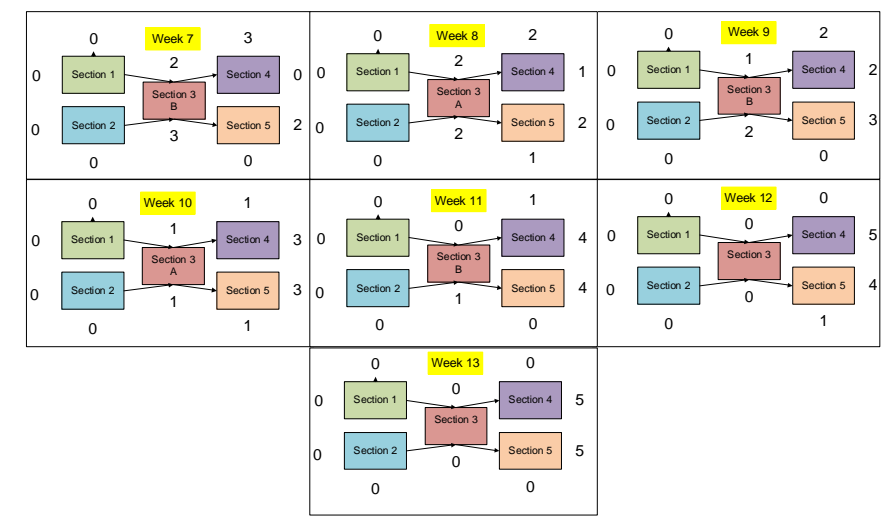

Fig. 4. Completion of orders

Starting from the 8th week, plot №4 begins systematically to produce the product for the product every week and due to the excess capacity in areas №4 and №5 already on the 12th week of the execution order of articles is completed "A" and on the 13th week execution order the product "B" ends. Following the results of the completion of the customer, there was charged interest in the order of articles " $\mathrm{A}$ " in the amount of $6 \%$ of the order value, and commissioned by the products "B" in the amount of $9 \%$ of the order value, which led to lower profits from orders for $37.5 \%$ of the planned profitability values. 
Now, let us consider how, in the same situation it would have worked as a synchronized manufacture control system (5) - (8). Each workshop section has one synchronization card. The solution of (5) - (8) becomes trivial, because the performance of the constraints imposed on the system, makes valid at each step only one solution. This situation is a direct consequence of the simplifications introduced in the demo.

The figure shows work №5 manufacture in the first three weeks. The difference is noticeable even in week №2, because the area already has product №3 "B" - station №2 in the second week and only at idle №3 week, when area №3 begins semi-processing "B" on section №2 and completes processing "B".

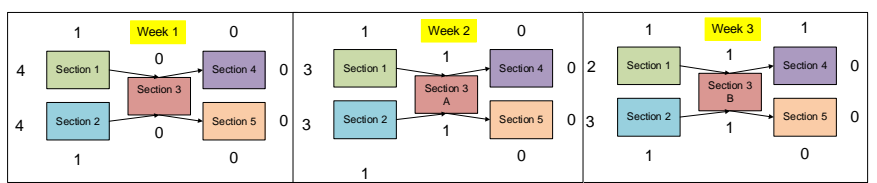

Fig. 5. A synchronized system in the first three weeks

Next, let us consider how the manufacture occurred in 4-6 weeks (Figure №6).

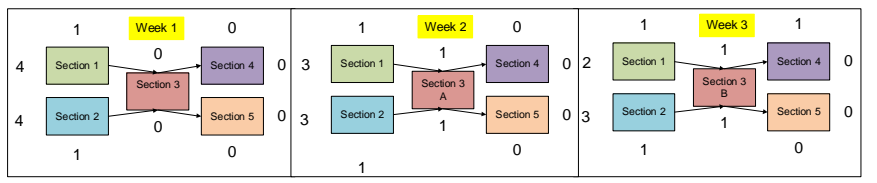

Fig. 6. Manufacture work in weeks 4-6

The manufacture chain of the product " $\mathrm{A}$ " forced idle because there is no free card synchronization - plot №4 does not release products. For this reason, section №3 only handles product "B". At first glance, the manufacture is not very different from each other.

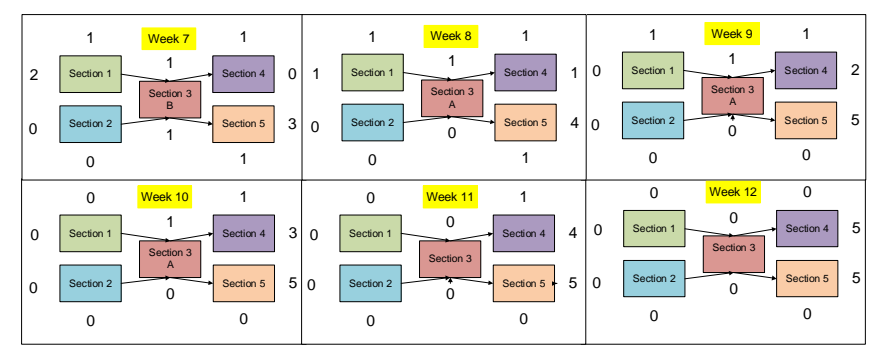

Fig. 7. Completion of orders in a synchronized system

Figure 7 presents final results of the synchronized manufacture management systems. The first and most obvious result of the system is that manufacture ended a week earlier. If you look closely, you can see that the manufacture of the product "B" was completed the 9th week, which is four weeks earlier than in the previous example and does not violate the time limit agreed in the contract.

When using synchronized manufacture management system, customers' penalties commissioned articles have been presented "A" in the amount of $6 \%$ of the order value. Profit from the sale of the two orders has decreased by $10 \%$ of the planned value. In comparison with the first case, it was possible to reduce the loss nearly four times! The profit gained from execution order is $30 \%$ higher than without the use of a synchronized control system.

Perhaps a test example might seem far-fetched, but the analysis of the practical experience of real industrial enterprises shows that in similar situations, the results tend to be worse.

\section{CONCLUSION}

The authors considered only the direct consequences of the synchronized approach to manufacture management. If we assess the level of work in progress and the timing and amount of assets frozen, it becomes obvious that the synchronized system allows one to reduce the time and other direct and indirect costs, exert a more positive impact on net profit.

For practical use of the proposed approach, it is required to develop an algorithm for solving the optimization problem (10), and implement a solution in automation system, integrated with the existing enterprise information system (ERP). The practical implementation of the small-scale synchronized manufacture management system will significantly improve the efficiency of manufacture, radically reduce the level of work in progress, manufacture cycle and manufacture costs. Additionally it will lead to a significant increase of the quality of planning, the relevance of the data in the system and improve the manageability of organizational manufacture.

\section{References}

[1] D. Gavrilov, Manufacture management on the basis of MRP II standard, $\mathrm{SPb}$.: Peter, 2002.

[2] H. Meyer, F. Fuchs, K. Thiel, Manufacturing Execution Systems: Optimal Design, Planning and Deployment, 2009.

[3] D. O'Leary, Enterprise Resource Planning Systems, Cambridge University Press, 2000.

[4] T. Ohno, Toyota Production System: Beyond Large-Scale Production, Cambridge, MA: Productivity Press, 1988.

[5] T. Hitoshi, The Synchronized Production System: Going Beyond JustIn-Time Through Kaizen, Kogan Page, 2006.

[6] R. Suri, It's About Time: The Competitive Advantage of Quick Response Manufacturing, 2003.

[7] M. Rother, Learn to see business processes. The practice of map value streams, Moscow: Alpina Business Books, 2005.

[8] D. Stamatis, Understanding overall equipment effectiveness, reliability, and maintainability, NY: CRS Press, 2010.

[9] E.B. Frolov "Manufacture logistics, or what is pulled shedule?", http://www.i-mash.ru/economy/7691-vytalkivajushhajavytjagivajushhaja-sistemy.html

[10] D. Hallett, "Pulling systems overview", 2009.

[11] S. Fedoseev, M. Gitman, V. Stolbov, A. Vozhakov, Controlproduct quality in modern industrial enterprises: a monograph, Perm: Publishing house of Perm. nat. issled. Polytechnic, 2011.

[12] S. Fedoseyev, A. Vozhakov, M. Gitman "Manufacture management on the tactical level of planning under the fuzzy initial information", Problems of management, vol. 5, pp. 36-43, 2009. 